\title{
Transformation of Countervailing Pow er in Collaborative Governance: A Case Study of the Shi-Hw a Sustainable Development Committee
}

\author{
Dong-Young Kim*
}

\begin{abstract}
The existence of adversarial countervailing power has been considered a necessary condition to making collaborative governance fair and effective. However, adversarial countervailing power cannot be easily transformed into a collaborative one that is more appropriate for collaborative governance. This article explores a mechanism of power transformation by bridging the theory of trust building and the theory of power in collaborative governance. This article posits that when there is distrust among parties, comprehensive, up-front prenegotiation on the structure of collaboration may set the stage for a small-wins approach to trust building by managing power imbalances. Power transformation may follow this trust-building cycle accordingly. The framework of power transformation is tested with the case of the Shi-Hwa Sustainable Development Committee, a successful experiment of collaborative governance in balancing development and environment in Korea in which adversarial countervailing power was transformed into a collaborative one. The results of this article imply that a key factor in successful collaborative governance is power management.
\end{abstract}

Keywords: Collaborative governance, adversarial countervailing power, trust building

\section{INTRODUCTION}

Collaborative governance can be defined as "a governing arrangement where one or more public agencies directly engage non-state stakeholders in a collective decisionmaking process that is formal, consensus oriented, and deliberative and that aims to make or implement public policy or manage public programs or assets" (Ansell \& Gash, 2008, p. 544). Much of the literature identifies power imbalances among the

* KDI School of Public Policy and Management. Email: dykim@kdischool.ac.kr.

Manuscript received November 9, 2014; out for review November 16, 2014; review completed December 11, 2014; accepted December 13, 2014.

The Korean Journal of Policy Studies, Vol. 29, No. 3 (2014), pp. 53-77.

(C) 2014 by the GSPA, Seoul National University 
parties as a commonly noted problem in collaborative governance, since power imbalances tend to discourage the parties from engaging in collaborative processes at the outset (Imperial, 2005; O’Toole \& Meier, 2004; Susskind \& Cruikshank, 1987; Warner, 2006), favor entrenched and concentrated parties (Edmunds \& Wollenberg, 2001; Leach, 2006; Yaffee \& Wondolleck, 2003), and produce distrust and dictating more adversarial behaviors among stakeholders (Calton \& Lad, 1995; Lane \& Bachmann, 1998; Vangen \& Huxham, 2003).

Much of the literature on collaborative governance thus likewise suggests that the existence of countervailing power may help to make collaboration fair, effective, and sustainable, since it can reduce, and even neutralize, the problems of power imbalances through a variety of mechanisms (Fung \& Wright, 2003; Mitchell, 2005; Purdy, 2012). The term "countervailing power," firstly formulated by John Kenneth Galbraith (1952) to describe the power of trade unions, citizen's organizations, and so on to offset business's excessive advantage, means here a form of power that develops to counter some well-established form of power advantage.

The forms of countervailing power, however, are likely to become excessively adversarial in confrontation with dominant and established forms of power. Conventional power balance processes that occur in the negotiation of controversial public issues, such as, for example, local sustainability, are often the stage for interest group politics, litigation, or social mobilization. The problem is that the forms and cognitive frames of adversarial countervailing power are not effective in bringing about successful collaboration. Different forms and cognitive frames of countervailing power, so-called collaborative countervailing power, are necessary for successful collaboration (Fung \& Wright, 2003).

Adversarial countervailing power, however, cannot easily be converted to collaborative purposes due to several inherent barriers (Fung \& Wright, 2003). Large organizations that possess adversarial countervailing power tend to engage in national or high-level policy rather than in local, practical problem-solving efforts. Also, their cognitive frames often involve narratives of inequity and disrespect, in other words, "injustice frames." These frames unambiguously assign culpability; they rigidly diagnose problems and prescribe fixed solutions, which in turn inhibits joint, flexible problem-solving collaboration. The political level at which such organizations tend to operate and their cognitive frames determine their competencies in the strategies of mobilization, persuasion, and threats. Also, psychological sources of solidarity and motivation often prevent them from transforming their cognitive frames and strategies into collaborative forms of governance.

How might adversarial countervailing power overcome these obstacles and be redeployed in collaborative contexts? How might actors who are accustomed to adversarial 
conflicts dramatically transform their cognitive frames and collaborate to formulate creative solutions? Fung and Wright (2003) posit that collaborative countervailing power will not be produced by supportive public policies, existing adversarial organizations, or even well-designed collaborative procedures in and of themselves. The dynamic whereby adversarial countervailing power is transformed into a collaborative one, however, is still vague and not understood clearly.

This article explores the dynamic of power transformation by combining the theory of trust building and the theory of power in collaborative governance. The next section addresses power dynamics in collaborative governance. The existence of adversarial countervailing power may manifest itself as distrust among the parties. Thus, the theory of trust building is considered in the following section to understand the relationships between power balancing and the trust-building cycle, and the article posits that powerbalancing prenegotiation for collaborative design may work as a catalytic starter for establishing a trust-building loop through which the transformation of countervailing power may follow accordingly. In order to test the proposed dynamic of power transformation, this article delves into the case of the Shi-Hwa Sustainable Development Committee, a local experiment of collaborative governance on a land-use planning and environmental management in South Korea.

\section{POWER IN COLLABORATIVE GOVERNANCE}

Facing the problem of power imbalances in collaborative governance, scholars and practitioners often suggest incomplete and even naive solutions. New governance proponents, whose orientation is mostly macro, implicitly suggest that gross imbalances of power among stakeholders can only be neutralized by certain collaborative institutional designs, such as the devolvement of decision-making power to local experimental deliberative groups (Fung \& Wright, 2003). On the other hand, others who concentrate on what goes on inside the collaborative procedure argue that so long as dialogue is properly and fairly organized at the procedural level, consensus can be reached (Faysse, 2006; Steins \& Edwards, 1999). Criticizing both macro- and micro approaches for not devoting systematic attention to pervasive problems of power imbalances, the proponents of so-called critical vision advise weak parties to reject participatory collaborative governance, since it is almost impossible to overcome power imbalances and very hard to build robust collaborative institutions (Edmunds \& Wollenberg, 2001).

Understanding how power relations shape the process of collaborative governance and outcomes may improve the quality of research on the effectiveness of power- 
balancing strategies. However, little theory exists to guide conveners, neutral practitioners, participants, and researchers in understanding power in collaborative governance (Huxham \& Vangen, 2005). Constructing a comprehensive framework to describe power in collaborative governance is not a simple task for a few reasons.

First, researchers are overwhelmed by myriad sources of power informed by a wide range of structural, relational, and cognitive factors and often inconsistent descriptions of power attributes and strategies (Hardy \& Phillips, 1998; Mooney, 1984). Although a few important efforts were made by negotiation researchers to provide comprehensive but parsimonious framework on bargaining power (Bacharach \& Lawler, 1980; Fisher \& Ury, 1981; Yukl \& Tracey, 1992; Kim et al., 2005), much work remains to be done to provide an adequate conceptualization of power dynamics in collaborative governance in the public sector.

Second, power is a matter of individual's subjective rather than objective perception, interpretation, and assessment of contexts or facts. And such subjective judgment is also a function of preferences, experiences, values, and how information is processed (Bacharach \& Lawler, 1976; Leap \& Grigsby, 1986). Consequently, it is almost impossible to construct a theoretical link between observable objective contexts as power sources and outcomes of observed power strategies without considering individual parties' power perceptions. In other words, different parties in the same objective circumstances may perceive and utilize their powers differently. Thus, in explaining power dynamics, any theory about power in collaborative governance should adequately deal with the role of individuals' perceptions of power.

Third, a few scholars have recently argued that a purely zero-sum, resource-based view of power in a competitive sense is inadequate in collaborative contexts (Fisher \& Ury, 1981). Fung and Wright (2003) propose that the adversarial characteristics of countervailing power, though not easily converted to collaborative ones, should be transformed into collaborative countervailing power for collaborative purposes. Huxham and Vangen (2005) describe three types of orientation to power- "power over" (oriented toward one's own interests) "power to" (oriented toward mutual interests) and "power for" (oriented toward the interests of others) — and suggest that "power over" can be transformed into "power to," and/or "power for" in order to advance the joint efforts of the collaboration. Such propositions indicate that understanding power in collaborative governance requires a dynamic model of power transformation.

\section{Sources of Power}

This article simplifies complex sources of power in collaborative governance, dividing them into four categories: 1) institutional arrangements and contexts, 2) solidarity- 
Table 1. Sources of Power in Collaborative Governance

\begin{tabular}{|c|c|c|c|c|}
\hline & \multicolumn{3}{|c|}{ Controllability } \\
\hline & & \multicolumn{3}{|c|}{ difficult to control $\leftarrow$ medium $\rightarrow$ easy to control } \\
\hline & & \multicolumn{3}{|c|}{ Deliberativeness } \\
\hline & & nondeliberative & hybrid & deliberative \\
\hline \multirow{3}{*}{ Location } & $\begin{array}{l}\text { outside } \\
\text { process }\end{array}$ & $\begin{array}{l}\text { institutional } \\
\text { arrangements } \\
\text { and contexts/ } \\
\text { solidarity-based } \\
\text { countervailing } \\
\text { coalitions }\end{array}$ & & \\
\hline & $\begin{array}{l}\text { boundary } \\
\text { of process }\end{array}$ & & $\begin{array}{l}\text { structure and } \\
\text { design of process } \\
\text { established through } \\
\text { prenegotiation }\end{array}$ & \\
\hline & $\begin{array}{l}\text { inside } \\
\text { process }\end{array}$ & & & $\begin{array}{l}\text { personal cognitive, } \\
\text { and analytic, } \\
\text { communicative } \\
\text { capacity }\end{array}$ \\
\hline
\end{tabular}

based countervailing coalitions, 3) structure and design of the process, and 4) personal cognitive, analytic, and communicative capacity. The four sources of power can be sorted out according to three dimensions: controllability, deliberativeness, and where the power source is located relative to the collaborative process (see table 1).

Controllability refers to the degree to which the parties can control the sources of power. Some sources of power, such as the legislation of favorable regulations, are usually beyond the control of the participants. Deliberativeness in the form of personal communicative capacity is a source of power that is inherently associated with the process. The sources of power in collaborative governance occupy various locations relative to the process. Some sources exist outside the process and others inside or on the boundary of the process.

\section{Institutional Arrangements and Contexts Outside the Process}

Some sources of power are embedded in institutional arrangements outside a collaborative governance process, or "away from the table" (Lax \& Sebenious, 1985). Those include legal provisions, regulations, and administrative procedures that allocate asymmetric power to the parties by effecting outside alternative courses of action by which they may address the issues. Technical, economic, or legal circumstances may 
also provide sets of possible alternative strategies that parties can draw on in problem solving. Those influential sources of power are usually nondeliberative, located outside the process, and beyond the control of the participants (Holzinger, 2001).

For example, some environmental laws in the United States, such as the Clean Air Act of 1970 and the Endangered Species Act of 1973, have citizen-suit provisions that entitle a private citizen to bring a lawsuit against another citizen, corporation, or government body for engaging in conduct prohibited by the statute (Babich, 1995). Potential lawsuits from citizens against usually strong parties, such as corporations or government agencies, often induce them to consider negotiation or collaborative procedures, such as the Habitat Conservation Plan (Thomas, 2003).

\section{Solidarity-Based Countervailing Coalition}

Solidarity-based countervailing power, which is another source of nondeliberative power, usually arises from a politically and socially organized group. And explanations of how such groups come to be and their strength are separated from, although linked to, the shape of collaborative institutions themselves and are contingent on factors that give rise to interest groups and social movements (Fung \& Wright, 2003). The bases of solidarity-based countervailing power are shared constructions of political meaning and psychological connection between and support from the members of the group. Since conflict provides the principal impetus for mobilization and solidarity (Sagoff, 2004), the very idea of solidarity-based countervailing power suggests the use of threats rather than collaboration to settle issues in dispute, and their capacities are well adapted to adversarial approaches, such as demonstrations, campaigns, petitions, and litigations (Fung \& Wright, 2003).

\section{Power Generated from the Structure of Collaborative Governance}

The design and structure of the collaboration process can provide opportunities for the exercise of power (Booher, 2004; Purdy, 2012; Vangen \& Huxham, 2003). For example, decisions regarding the collaboration's agenda provide a very important opportunity for the use of power (Altheide, 1998, Eden \& Huxham, 2001) since they reveal who has a legitimate claim to participate in the process (Gray, 1989). In addition who will participate in the collaboration as potential allies, which facts should be appealed to in finding solutions, and how decisions will be made are also related to the question of who has power to control the process. Thus, the design and structure of the collaboration process signals which participants hold the most power and who will take credit for the joint effort (Purdy, 2012; Vangen \& Huxham, 2003). 
Fung and Wright (2003) maintain that the specific structures of institutions of collaboration are themselves the result of endogenous political processes. Their structures hinges on configurations of institutional settings and nondeliberative social forces outside collaborative governance. For example, when countervailing power is weak, concentrated parties control the rules of collaboration in such a way as to favor their interests by limiting the collaboration agenda, restricting the range of participants, and reducing collaborative input to mere advice (Fung \& Wright, 2003).

Negotiation and dispute resolution literature likewise emphasizes the influence of prenegotiation in designing the process in such a way as to encourage participation (Cormick, 1989; Saunders, 1991). Unless participants feel it is possible to reconcile their differences fairly given the balance of power among the parties that is manifested in the structure of the collaborative process, they may not be interested in participating in collaboration or negotiation.

\section{Personal Capacity Inside the Collaborative Process}

One of the main arguments against collaborative governance and deliberation is that even fair rules, regulations, and well-designed collaborative procedures will not in and of themselves balance power among participants completely since individual cognitive, analytic capacities can introduce pervasive asymmetry (Edmunds \& Wollenberg, 2001; Sanders, 1997).

These arguments mostly concern how such asymmetries influence deliberation inside the collaboration procedure. For example, some participants are inherently better than others at articulating their arguments in reasonable terms and creating persuasive memos and documents (Phillips \& Hardy, 1997; Sanders, 1997). Systematically and materially underrepresented and disadvantaged groups, such as racial minorities and poorer people, are less likely to have learned such communication skills and to have a wide range of knowledge, expertise and information (Gunton \& Day, 2003; Lasker \& Weiss, 2003; Warner, 2006). Discourse and prescriptive negotiation theories also point to the deployment of various individual capacities, such as active listening skills, the ability to control emotions, and creativity, and the use of external standards of legitimacy inside the negotiation process as important sources of negotiation power (Fisher \& Ury, 1981; Holzinger, 2001). 


\section{DYNAMIC MODEL OF TRANSFORMATION OF COUNTERVAILING POWER IN COLLABORATIVE GOVERNANCE}

This section proposes a dynamic model of the transformation of countervailing power in collaborative governance as shown in figure 1 below. Adversarial countervailing power, built up by weak parties who tap into many sources of power, often creates a mutually destructive stalemate. Such policy deadlocks or failures caused by conventional adversarial approaches may help the parties see their interdependence and provide the ultimate impetus for them to talk (Bryson et al., 2008; Futrell, 2003; Weber, 2003; Zartman, 1989). Some scholars argue that such interdependency helps stakeholders overcome any prehistory of antagonism and build trust (Ansell \& Gash, 2008; Imperial, 2005; Logsdon, 1991; Thomson \& Perry, 2006; Yaffee \& Wondolleck, 2003).

However, seeking a way out of a policy deadlock is not always adopted and turned into successful collaboration. Even if the parties seize the moment and sit together at the table, they still may not trust each other (Weech-Maldonado \& Merrill, 2000). They may not be sure whether the other parties truly desire to collaborate, want to delay the process, or use collaboration as window-dressing (Futrell, 2003). They may participate in a collective forum not because they have a vision of what they might accomplish through collaboration but because they worry about what might happen without their participation (Susskind \& McMahon, 1985). Although the hypothesis that a policy deadlock may be a necessary context to initiate a trust-building cycle is

Figure 1. Dynamic Model of Transformation of Countervailing Power in Collaborative Governance
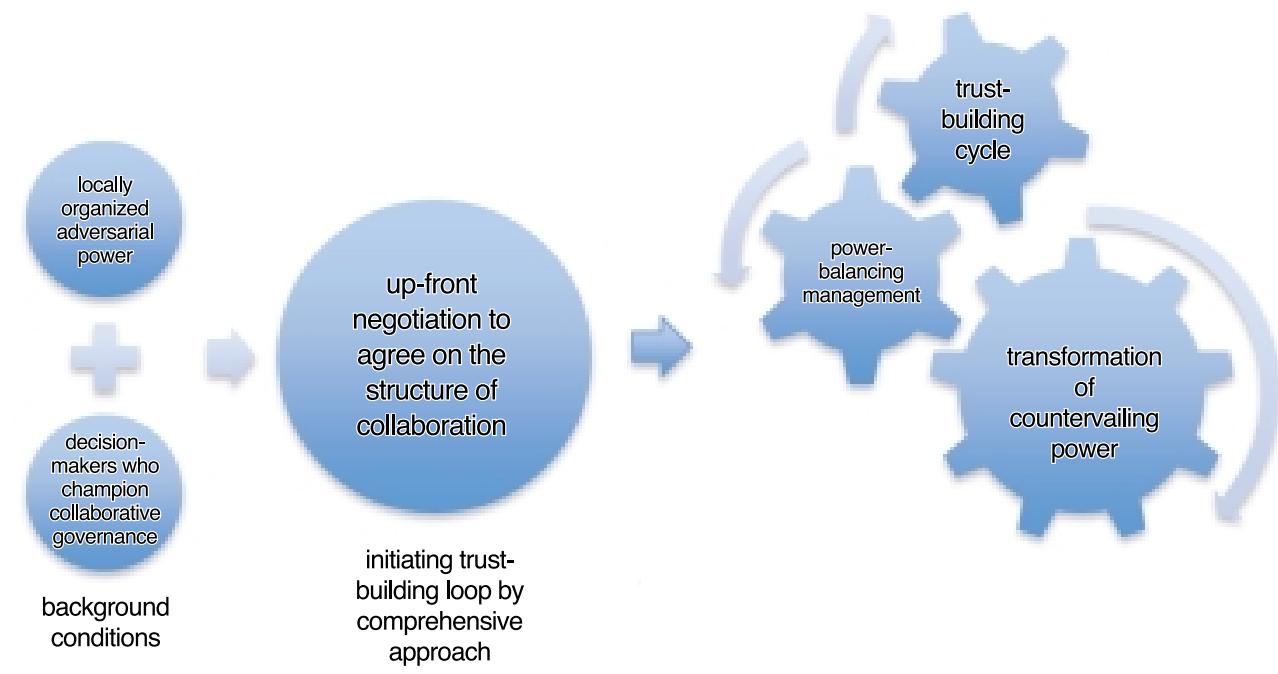

The Korean Journal of Policy Studies 
compelling, it is not enough to explain what happens inside the process to build trust.

Also, a prolonged conflict is likely to create a vicious cycle of suspicion, distrust, and stereotyping (Ansell \& Gash, 2008). Thus, the lack of trust or distrust among the parties is a common starting point for a collaborative process (Vangen \& Huxham, 2003; Weech-Maldonado \& Merrill, 2000), and trust building is the most difficult component in collaborative process among historically antagonistic and distrusted organizations (Murdock et al., 2005). How to build trust in such an environment and how to sustain it during the collaborative process are very important matters in practice.

Transforming adversarial countervailing power into a collaborative one also requires a dramatic shift of the cognitive frames through which the parties understand the political world, articulate solutions to problems, and mobilize support for themselves. Moreover, transformed cognitive frames require different sets of competencies and skills as shown in table 2 (Fung \& Wright, 2003; Putnam, 2004).

The difficulty of transformation may imply that the transformation process should

Table 2. Differences between Adversarial and Collaborative Countervailing Power

\begin{tabular}{|c|c|}
\hline $\begin{array}{l}\text { Sources and Forms of Adversarial } \\
\text { Countervailing Power }\end{array}$ & Countervailing Power \\
\hline $\begin{array}{l}\text { relies on threats and mobilization } \\
\text { maximizes interests by seeking to get the } \\
\text { government to rule in its favor, typically through } \\
\text { bargaining process } \\
\text { emphasizes differences between groups rather } \\
\text { than their commonalities } \\
\text { ignores other interests } \\
\text { Political Scale: } \\
\text { influences high-level policy } \\
\text { Competencies: } \\
\text { strategies of communication, information } \\
\text { provision, and persuasion to mobilize broad } \\
\text { popular support and mount pressure } \\
\text { Cognitive Frames: } \\
\text { informed by injustice frames (inequity and } \\
\text { disrespect) } \\
\text { assigns culpability (incriminates adversaries) } \\
\text { prescribes simple and direct policy solutions } \\
\text { represents positions in absolute terms } \\
\text { offers rigid diagnoses }\end{array}$ & $\begin{array}{l}\text { relies on reason. } \\
\text { solves problems } \\
\text { discovers the broadest commonality of } \\
\text { interests rather than mobilizes maximum } \\
\text { support for given interests } \\
\text { encourages mutual acknowledgment and } \\
\text { appreciation } \\
\text { Political Scale: } \\
\text { operates at very local levels } \\
\text { Competencies: } \\
\text { deliberation, problem-solving negotiation } \\
\text { Cognitive Frames: } \\
\text { depends on sustained and deep cooperation } \\
\text { between diverse parties } \\
\text { discovers and tests hypotheses about the } \\
\text { complex causes of public problems } \\
\text { offers more flexible diagnoses }\end{array}$ \\
\hline
\end{tabular}


be gradual or incremental. And much literature hints that an incremental trust-building process through power-balancing management may be related to the transformation of cognitive frames embedded in countervailing power. Huxham and Vengen (2000) suggest that coming to terms with the issues of perceived power imbalances is likely to require many cycles of the trust-building cycle. Norris-Tirrell and Clay (2010) argue that concern for others' interests is most likely to emerge under conditions of trust. Vengen and Huxham (2013) posit that a high level of mutual trust between parties could increase the satisfaction level them all even if one party is dominant. Thus, once a trustbuilding cycle in a collaborative process is successfully launched in a well-intentioned way, the transformation of countervailing power is likely to start accordingly.

Much literature suggests that trust building is a cyclical process in which trust is built incrementally with each positive outcome (Huxham, 2003; Imperial, 2005) and that a "small wins" approach (Bryson, 1988), which relies on successful implementation of low-risk initiatives, is a pragmatic way to initiate a trust building loop (Das \& Teng, 1998; Vangen \& Huxham, 2003). However, initiating a trust-building cycle with the small-wins approach requires at least certain amount willingness of the parties to take the risk required to set the process in motion (Webb, 1991; Vangen \& Huxham, 2003).

In order to launch the trust-building cycle in a context of distrust among the parties, there have to be conditions under which the trust-building cycle could be initiated. The proposed model in this article suggests two background conditions and one dynamic factor for initiating a trust-building cycle through which the transformation of countervailing power can happen. Fung and Wright (2003) suggest two conditions as sources of collaborative countervailing power. First, locally organized entities with deep local knowledge are more likely to give up adversarial modes of participation for collaborative ones than groups operating at broader levels. Second, political leaders may champion participatory collaboration to create venues for problem solving.

If these two conditions are present, then the parties will be in a position to negotiate the structure of collaboration in such a way as to manage power imbalances, which can serve as the seed for initiating the trust-building loop. The structure of collaboration, such as the range of participants, the scope of agendas, and the purpose of collaboration, is closely related to trust building since in it reside the inherent sources of power with which the parties may want to protect and advance their interests (Eden \& Huxham, 2001; Huxham \& Vangen, 2000). Consequently, perceived power imbalances embedded in the structure of collaboration are likely to produce a perception of weakness that in turn induces a perception of vulnerability, making the weak parties reluctant to trust powerful ones and defensive about their own agendas (Lane \& Bachmann, 1998; Lawler, 1992; Vangen \& Huxham, 2003).

Thus, managing power imbalances in an effort to design the structure of collabora- 
tion is very important for initiating a trust-building loop when there is lack of trust or distrust among the parties from the beginning. Trust requires forming expectations about the way others will contribute to achieving the collaborative outcome (Lane \& Bachmann, 1998) and the willingness to take the risk that other parties may take advantage of collaborative efforts with opportunistic behaviors (Vangen \& Huxham, 2003). Thus, agreeing on the structure of collaboration in advance helps the parties to form necessary expectations and reduce the risk inherent in collaboration (Gulati, 1995). In doing so, the parties may create the trust necessary to initiate trust-building loop with a small-wins approach thereafter.

\section{TESTING THE MODEL WITH A CASE STUDY}

This section tests the proposed dynamic model of the transformation of countervailing power in collaborative governance by considering the case of the Shi-Hwa Sustainable Development Committee as an example of successful collaborative governance in balancing development and environment in Korea. This case is very appropriate for testing the model since the parties involved in development projects in the Lake Shi-Hwa region were successful in transforming an almost ten-year adversarial conflict into a collaborative one, despite the lack of trust among actors. I introduce the case by describing the Korean context as a backdrop to it. For the case study, this article draws on secondary sources, such as academic journal articles and news articles. In addition, key stakeholders, such as a number of leading members of the committee were interviewed face-to-face occasionally at academic conferences and training programs for conflict resolution during 2010 and 2012. These interviews made it possible to glean their perceptions of the collaborative process and trace their cognitive frameworks through it.

\section{Background}

South Korea achieved rapid economic development with a "grow first, clean up later" approach that was propagandized by authoritarian military regimes beginning in the mid-1960s (Moon \& Lim, 2003) and saw the burgeoning of civic rights during the democratic consolidation that subsequently emerged. Serious environmental fatigue stemming from rapid economic development can trigger social movements on the part of environmental groups and victimized citizens (Cotton, 1998), and this was the case in Korea. Without facilitative leadership and a regulatory framework to support collaboration, however, conventional balancing processes with respect to sustainability 
have been excessively adversarial in Korea due to confrontation between the dominant paradigm of economic development and the emergence of countervailing power through interest group politics, litigation, and social mobilization. Conditions thus obtain in Korea that make it possible to conduct a sort of "natural experiment" to analyze how to transform adversarial countervailing power to collaborative countervailing one.

\section{Lake Shi-Hwa and Regional Development Plans}

Lake Shi-Hwa is an artificial lake on the west coast of Republic of Korea. ${ }^{1}$ The 12.6 kilometer-length tidal embankment was built between 1986 and 1994 as a means of sealing off the mouths of the bay (figure 2) so as to reclaim 133.7 square kilometers of land for agricultural use and industrial complexes and create 42.3 square kilometers

Figure 2. Lake Shi-Hwa and Surrounding Region

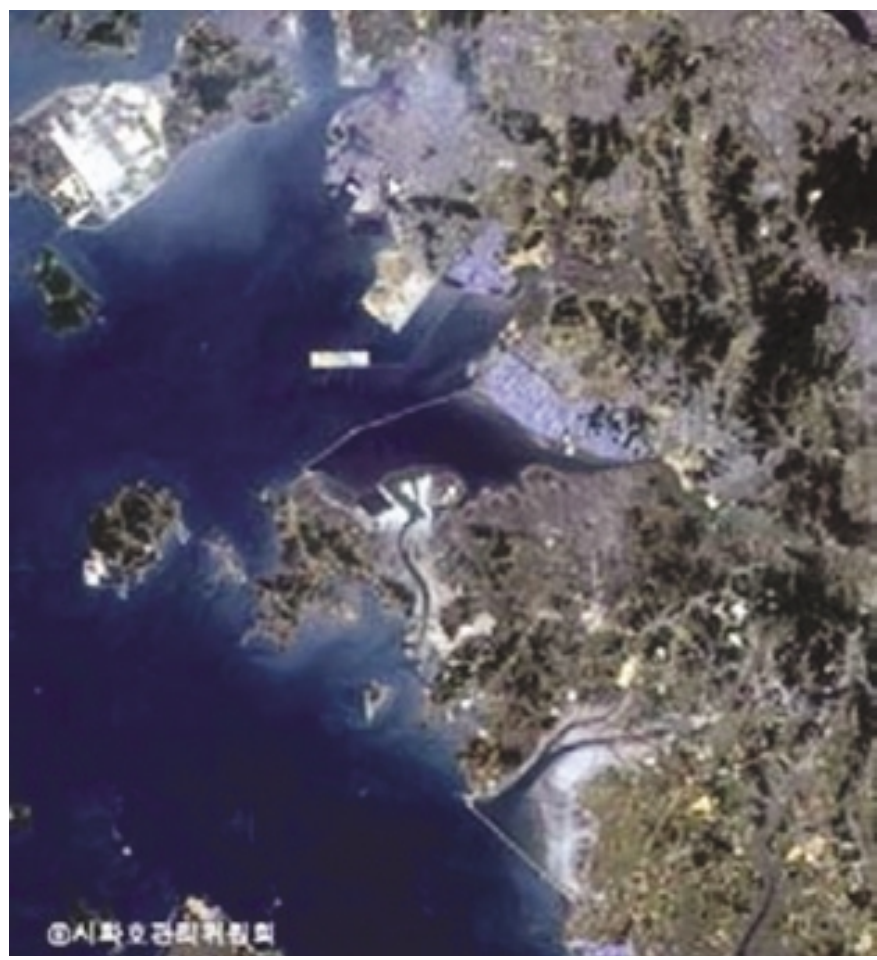

Source: Lake Shi-Hwa Management Committee

1. Shi-Hwa was named after the first syllables of the names of the two cities, Shi-Heung and Hwa-Sung, that surround the lake. 
for a freshwater lake to irrigate the Shi-Hwa region. This ambitious reclamation project was the byproduct of a government decision in 1977 to designate the area adjacent to the bay as a special development area, where An-San, a new town, and Pan-Wol, an industrial complex, would be built to which people and factories would be moved from Seoul in order to alleviate the overpopulation problem in the capital city (Lee, 2012).

\section{Lake Shi-Hwa Environmental Disaster}

After the lake was finally sealed off in 1994, its water quality began rapidly degrading due to an increasing pollution load from residential areas and industrial complexes and the lack of wastewater treatment facilities. A large-scale seawall was constructed to remove the mudflat, which reduced the natural pollution-absorption capabilities of the lake while blocking seawater inflow. In 1997, Lake Shi-Hwa became a symbol of environmental disaster in Korea. Water pollution of the lake raised social and environmental concerns, which led to conflict between the government and angry residents. Apart from water pollution, air pollution from factory stacks and noisome odor were serious problems to the residents near the lake.

\section{Successful Collaborative Governance}

Miraculously, Lake Shi-Hwa and adjacent regions turned themselves from a case of environmental disaster into a model for sustainable development relatively in a short period of time. The annual mean chemical oxygen demand concentration in the streams flowing through the industrial complex near Lake Shi-Hwa decreased from 1,970 parts per million in 2004 to 17 parts per million in 2006. And the chemical oxygen demand of Lake Shi-Hwa improved significantly to 2 parts per million in the same year. As the water quality improved, the ecosystem in the region was also revived with more migratory birds and fishes. The number of complaints of bad odors decreased from 630 cases in 2004 to 190 in 2008.

Improvements in environmental quality were made through the implementation of the agreements on water and air quality improvement roadmaps and regional development plans that the Shi-Hwa Sustainable Development Committee hammered out in negotiations and deliberation over a four-year period, from 2004 to 2008. A total of 38 members participated in the committee, including 4 local politicians as board members, 2 joint chairs, 12 government officials from central and local governments, 4 officials from public corporations, and 16 members of the Shi-Hwa Coalition.

The committee generated lots of creative ideas for developing the area in more sus- 
tainable ways. For example, they agreed to establish and conserve a habitat for migratory birds in reclaimed lands and an eco-network in the newly developed city for wild animals to move safely in. They formulated stringent guidelines for constructing environmentally friendly golf courses around the new city. They designated a site of dinosaur egg fossils for eco-tourism and sought to conserve narrow-mouth frogs by moving their habitat into another appropriate region. They also agreed to earmark all the revenue from regional development projects for environmental management plans to improve air and water quality in that region. Acknowledging the efforts of the committee and its tangible outcomes, in 2008, the government institutionalized it, turning what started as an ad-hoc voluntary process into a permanent, legitimate, and official decisionmaking body.

\section{Transformation of Adversarial Countervailing Power into a Collaborative One in the Shi-Hwa Sustainable Development Committee}

This section applies the proposed model of power transformation to the case of the Shi-Hwa Sustainable Development Committee and focuses on the relationships among power, trust building, and transformation.

\section{Adversarial Countervailing Power against the Government}

Local civil societies, including environmental groups in the region, had over time built up enough substantial countervailing power to create policy deadlocks. Their first source of power was a solidarity-based countervailing coalition that relied on mostly mass rallies and other public activities.

After the Ministry of Environment discharged polluted water from Lake Shi-Hwa into the sea in order to alleviate water pollution in the lake in 1996, tens of thousands of fishes and shellfish died around the bay. Consequently, local fishermen and environmental groups fiercely complained about the government decision. A number of government agencies came up with various policy packages to address environmental problems and development interests, but the citizens in the region likewise took action: in 1999, 12 civil organizations in that region established a civic coalition and began organizing systematic campaigns to challenge government decisions.

For example, on March 22, 1999, they convened a civil forum on Lake Shi-Hwa in which 500 people participated to celebrate World Day for Water. They also organized a workshop to formulate their own proposal that included construction of an ecopark around Lake Shi-Hwa. They explored the area and incidentally found the fossils of dinosaurs' eggs in a reclaimed area. In 2000, they intentionally derailed official public 
hearings on a farmland development plan proposed by the Ministry of Environment and organized a mass rally in front of the central government complex in Seoul.

The Ministry of Maritime Affairs and Fisheries organized local forums that 24 local stakeholders participated in to establish a comprehensive management plan for the region. However, the local forums excluded the coalition members. The Ministry of Construction and Transportation also made an effort to create a comprehensive management plan for Lake Shi-Hwa aimed at reclaiming more land by establishing the Shi-Hwa Region Policy Council, whose members included central government agencies, local governments, and public corporations. The council commissioned six national think-tank institutes to formulate a comprehensive management plan for the Lake Shi-Hwa region. The proposal outlined the Shi-Hwa Multi-Techno Valley project, whose goal was to turn reclaimed areas into an industrial complex for cutting-edge technology industries and venture companies as well as to establish tourism and leisure sites. The Lake Shi-Hwa Coalition, however, criticized the proposal as another deadly governmental blunder that would end up polluting Lake Shi-Hwa again. The coalition blocked every step of the process. The public hearing on the proposal by the Ministry of Construction and Transportation was not conducted properly due to the protest of coalition members.

\section{Role of Contexts outside the Process}

Although adversarial countervailing power might pressure a government to consider other options to address a problem than unitary, preemptive actions, pressure can also come from contexts outside the process. The strong resistance from the Shi-Hwa Coalition was accompanied by criticism of the government by politicians and the media for its failure in managing water quality in Lake Shi-Hwa. Even the Board of Audit and Inspection, a powerful independent body of the government, criticized the central government agencies that were responsible for development projects and environmental management. Those critiques from contexts the groups directly involved in challenging the government weakened its power further.

Another meaningful change in the political realm that affected the government agencies that contributed to the environmental disaster was President Roo Moo-hyun's introduction of a so-called participatory government that emphasized the value of participatory decision making. In addition, the new administration recruited civil leaders into government positions. Thus, people affiliated with civil organizations were able to connect with the senior bureaucrats of many government agencies. A new political atmosphere might encourage government officials to try to make the decision-making process more inclusive. 


\section{Distrust among the Parties}

When the Ministry of Construction and Transportation invited the Shi-Hwa Coalition to hash out the problem in a new collaborative process, the coalition did not accept the offer right away. Its members did not trust the government. They believed that water quality improvement should be the priority, but the government argued that water quality improvement and regional development should go hand in hand. Even though the government promised that some portion of the revenues from regional development would be earmarked for environmental management projects in Lake Shi-Hwa area, the members of the Shi-Hwa Coalition suspected that the government would manipulate them to agree to the project first and then change its stance and adopt a passive role in environmental management.

\section{Up-front Negotiation to Agree on the Structure of Collaboration}

One of the reasons why the Shi-Hwa Coalition did not accept the offer from the ministry right away was that an immediate acceptance might have weakened its solidarity as a coalition and signaled its weakness to the government. Although the coalition realized that the water quality of the lake had not been improved at all despite their efforts to tackle the problem through antigovernment campaigns, the coalition did not see any other options but to maintain their adversarial stance because they distrusted the government.

Even when the Shi-Hwa Coalition did finally accept the invitation from the ministry, it proposed a few counterterms as conditions to begin any dialogue. First, a new collaborative working group should not limit participants and should be open to anyone who wanted to participate. Although the government had tried to incorporate civilian members into some phases of decision-making process, the members of the Shi-Hwa Coalition had been excluded. Second, any decision should be arrived at by consensus rather than a majority rule. Third, the dialogue should be transparent and open to the public through a web page that would update information on meetings and would post relevant data and even recorded transcripts from the meetings. Fourth, the Shi-Hwa Coalition should be allowed to recommend any experts to the committee. Fifth, any discussion should start from scratch. And sixth, all information about the government project should be shared with participants of the committee in a timely manner (Hong \& Lee, 2008).

According to an interview with the leader of the Shi-Hwa Coalition who proposed these terms to the government, the coalition did not expect that the Ministry of Construction and Transportation would accept them. If the ministry had refused to accept 
the terms, that refusal could have been utilized as a rationale for the coalition to criticize the government even more harshly. To the surprise of the coalition, however, the government official from the ministry accepted all the terms. Although the coalition members were suspicious because this was such an unusual move on the part of the government, they decided to join in a new multistakeholder process called the ShiHwa Sustainable Development Committee on January 16, 2004.

When the government official from the Ministry of Construction and Transportation proposed a new collaborative process and accepted all the preconditions set by the Shi-Hwa Coalition as preconditions, he was criticized inside the government on the grounds that accepting the terms might make the government look weak and signal that the government had surrendered their own decision-making power mandated by the law. The leaders of the Shi-Hwa Coalition who decided to participate in the process were also under pressure from members of the Coalition who were afraid that they might be co-opted or manipulated by the government.

At the first meeting of the Shi-Hwa Sustainable Development Committee, the participants introduced ground rules specifying and elaborating on the terms that the Shi-Hwa Coalition had proposed. The chairman of the committee was the senior government official from the Ministry of Construction and Transportation for the first couple of meetings. But later the senior official suggested that the committee should have two joint chairpersons, one from the government and one from civil society. The committee established three subgroups: one for air quality, one for water and the ecosystem, and one for regional development planning. The chairperson for each of the subgroups was selected by the Shi-Hwa Coalition, while government officials served as facilitators. With this arrangement, the committee managed to achieve a balance of power between the government and civil society.

The up-front negotiation regarding the structure of the collaboration was critical to its success. In the eyes of the coalition, the terms it had proposed had power-balancing effect. The expectation that the process would be inclusive and transparent and that consensus rather than majority rule would decide the outcome of any decision made the coalition feel less vulnerable and less distrustful and helped reduce the risk inherent in collaboration that it exposed itself to in working with the government.

\section{Small-Wins Approach to Trust Building and Power Transformation}

At the early stage of the collaborative process, the members of the Shi-Hwa Coalition could not fully trust the government. According to an interview with the leader of the Shi-Hwa Coalition, however, trust between the government and the Shi-Hwa Coalition members started being built up little by little when the members of the coalition saw 
that the government was indeed going to honor the terms the coalition had set. For example, when the coalition requested copies of technical and administrative documents about development projects from the Ministry of Construction and Transportation, government officials sent all the relevant documents to it in a timely manner. Also, the webpage of the Shi-Hwa Sustainable Development Committee through which the public was able to access much information on its meetings increased the level of transparency, which also contributed to building trust among its members.

\section{Transformation from Mobilizing to Win to Solving Local Problems}

One of the major transformations of the Shi-Hwa Coalition as adversarial countervailing power was its decision to focus on local problem solving rather than coalition building with other major environmental organizations whose headquarters were located in the capital. Although it had the opportunity to form a coalition with these major organizations, it decided instead to work only with its local members and focus on its own local problems (Ma \& Moon, 2012).

The leader of the coalition revealed in the interview that he was concerned that the involvement of the major environmental groups from Seoul might lead the process into deep-value-rooted conflict rather than problem-solving deliberation. The coalition also believed that it could only trust the government participants to the extent that it did not feel vulnerable and that working with large groups from the capital would make it feel weaker. In addition, the coalition believed that its members were better positioned to discuss local issues, as they possessed more information about what was happening on the ground than the national groups in Seoul did.

\section{Transformation from Culpability to Mutual Learning}

Usually, the parties in adversarial relationships do not acknowledge each other's concerns but instead tend to criticize or attack them. Such interaction begets more defensive and aggressive strategies. Acknowledging that conventional argumentative processes had prevented each group from learning from the other the Shi-Hwa Sustainable Development Committee sought to overcome this obstacle by holding special sessions for mutual learning, so-called, learning without criticism" sessions (Lee \& Ahn, 2007).

The ground rules for these learning without criticism sessions were that no participant should criticize another participant. Instead, the members were meant to just listen the experts who presented conflicting views to the whole session and only speak to ask these experts to clarifying questions. For example, during two-day sessions on the 
issue of environmentally friendly golf courses, the participants listened to experts without raising any challenges, and the result was that they learned about the potential risks of such golf courses and their impact on the region's ecosystem and about ways of designing golf courses and available technologies that could minimize the environmental damage from building them. Over the first five years of the collaboration, the Shi-Hwa Sustainable Development Committee held 35 learning sessions.

\section{Transformation from Rigid Diagnoses to Flexible Joint Fact-Finding}

The Ministry of Construction and Transportation proposed to develop 10.46 square kilometers of reclaimed land for the Shi-Hwa Multi-Techno Valley Project. However, the Shi-Hwa Coalition strongly argued that the ministry should reduce the size of the development area to only 3 square kilometers. The participants could not resolve this disagreement due to conflicting data and the opinions of a number of adversarial experts. Thus, they agreed to commission a joint research project that experts from each side would participate equally in to figure out the appropriate size of the development. After a long-term study, the joint research team recommended that the government should establish the Shi-Hwa Multi-Techno Valley Project on a 9.26 square kilometer parcel. The size that the team proposed was slightly smaller than that originally planned on by the government, but it was much larger than that suggested by the ShiHwa Coalition. Significantly, the coalition members accepted the recommendation from the joint research team, since their own experts had also participated in the joint research process, from designing research questions to collecting data.

\section{Challenges during the Process}

The members of the Shi-Hwa Coalition who built trust incrementally and transformed their cognitive framework from an adversarial one into practical problem-solving one became deeply committed to the self-governance of the process, sensing that they owned it, and they tried to maintain the momentum. Consequently, they could support the agreement the parties arrived at at the end of the process. However, some members were not satisfied with the outcome that would allow the government to establish another industrial complex on the reclaimed area. Those members finally walked out of the process, built another coalition with other sympathetic environmental groups, and accused the Shi-Hwa Sustainable Development Committee of having been manipulated by the government (Lee \& Hong, 2009; Jun, 2011). But the fact that all major stakeholders agreed on the decisions and that most of the local residents supported the agreement enhanced the legitimacy of the agreement. 


\section{CONCLUSION}

Collaborative governance is an institutional arrangement that can improve the effectiveness and legitimacy of public decision making. That experiments of collaborative governance around various controversial issues arise voluntarily, transform adversarial relationships into collaborative ones, and even produce tangible, positive outcomes might be more of a miracle, however, than something we can take for granted.

This article has tried to test the framework of power transformation by considering the case of the Shi-Hwa Sustainable Development Committee as a successful experiment of collaborative governance whereby of adversarial countervailing power was transformed into a collaborative one in balancing development and environment in Korea. The framework is quite useful in explaining how an adversarial coalition that had battled the government for more than 10 years could transform into very successful collaborative one. Only when the Shi-Hwa Coalition as a locally organized group felt that power among the parties was roughly had been balanced through up-front negotiation over the structure of the collaborative process was it able to start incrementally gaining trust in the government.

The results of this article may provide some guidance for decision makers and practitioners who consider collaborative governance to be an alternative approach to solving controversial problems but who find themselves in situations in which there serious distrust among the parties owing to their perception of a serious power imbalance. The key factor that may lead to successful collaborative governance is effective power-balancing management, since power transformation can hinge on trust building, which in turn depends on securing a balance of power.

Thus, scholars and practitioners need to have a clearer understanding of the mechanisms and dynamics of power balancing in and around collaborative governance. If we understand why certain parties perceive power imbalances, it will be easier to remedy the problem. Taking into account how difficult or easy it is to controlling a given power source, scholars and practitioners should focus on up-front negotiations over the structure of collaborative governance as a more appropriate method for power management when there is distrust among the parties but should also keep working to change institutional arrangements in such a way as to secure a balance of power outside the collaborative process.

This analytic framework may have a limitation in that it is not necessarily generalizable. The proposed model was only tested with the single case of the Shi-Hwa Sustainable Development committee. However, there are many potential cases in Korea that this model could be tested on, including controversies over where to site nuclear power plants, high-level nuclear waste treatment facilities, and high-voltage transmission 
towers. Further research is necessary to determine whether the proposed model could be applied to these cases.

Second, there may be other important factors that contribute to managing power during the collaborative process. For example, the leadership of trusted facilitator or mediator is widely considered to be critical in bringing parties to the table and in empowering and representing weaker stakeholders through procedures that help put stakeholders on an equal footing (Ozawa, 1993). Where incentives to participate are weak, power and resources are asymmetrically distributed, and preexisting antagonisms are strong, leadership becomes all the more important. In the case of the Shi-Hwa Sustainable Development Committee, there was no neutral third party, but further study is needed to identify the potential role of facilitative leadership in the dynamic model of transformation of countervailing power in collaborative governance.

\section{REFERENCES}

Altheide, D. L. 1988. Mediating cutbacks in human services: A case study in the negotiated order. Sociological Quarterly, 29(3): 339-55.

Ansell, C., \& A. Gash. 2008. Collaborative governance in theory and practice. Journal of Public Administration Research and Theory, 18(4): 543-571.

Babich, A. 1995. Citizen suits: The teeth in public participation. Environmental Law Reporter, 25(1): 10141.

Bacharach, S. B., \& E. J. Lawler. 1976. The perception of power. Social Forces, 55(1): 123-134.

Bacharach, S. B., \& E. J. Lawler. 1980. Power and politics in organizations. San Francisco: Jossey-Bass.

Booher, D. E. 2004. Collaborative governance practices and democracy. National Civic Review, 93(4): 32-46.

Bryson, J. 1988. Strategic planning: Big wins and small wins. Public Money and Management, 8(3): 11-15.

Bryson, J. M., \& B. C. Crosby. 2008. Failing into cross-sector collaboration successfully. In L. B. Bingham \& R. O’Leary (eds.), Big ideas in collaborative public management (pp. 55-78). Armonk, NY: M. E. Sharpe.

Cormick, G. W. 1989. Strategic issues in structuring multi-party public policy negotiations. Negotiation Journal, 5(2): 125-132.

Cotton, J. 1998. From authoritarianism to democracy in South Korea. Political Studies, 37(2): 244-259.

Das, T., \& B. Teng. 1998. Between trust and control: Developing confidence in partner 
cooperation in alliances. Academy of Management Review, 23(3): 491-512.

Eden, C., \& C. Huxham. 2001. The negotiation of purpose in multi-organizational collaborative groups. Journal of Management Studies, 38(3): 373-391.

Edmunds, D., \& E. Wollenberg. 2001. A strategic approach to multistakeholder negotiations. Development and Change, 32(2): 231-253.

Faysse, N. 2006. Troubles on the way: An analysis of the challenges faced by multistakeholder platforms. Natural Resources Forum, 30(3): 219-229.

Fisher, R., \& W. L. Ury. 1981. Getting to YES: Negotiating agreement without giving in. New York: Penguin.

Fung, A., \& E. Olin Wright. 2003. Countervailing power in empowered participatory governance. In A. Fung \& E. Olin Wright (eds.), Deepening Democracy: Institutional Innovations in Empowered Participatory Governance (pp. 259-289). London: Verso.

Futrell, R. 2003. Technical adversarialism and participatory collaboration in the U.S. chemical weapons disposal program. Science, Technology, and Human Values, 28(4): 451-482.

Galbraith, J. K. 1952. American capitalism: The concept of countervailing power. Boston: Houghton Mifflin.

Gray, B. 1989. Collaborating: Finding common ground for multi-party problems. San Francisco: Jossey-Bass.

Gulati, R. 1995. Does familiarity breed trust? The implications of repeated ties for contractual choice in alliances. Academy of Management Journal, 38(1): 85-112.

Gunton, T. I., \& J. C. Day. 2003. The theory and practice of collaborative planning in resource and environmental management. Environments, 31(2): 5-19.

Hardy, C., \& N. Phillips. 1998. Strategies of engagement: Lessons from the critical examination of collaboration and conflict in an interorganizational domain. Organization Science, 9(2): 217-230.

Holzinger, K. 2001. Negotiation in public policy-making: Exogenous barriers to successful dispute resolution. Journal of Public Policy, 21(1): 81-106.

Hong, S., \& J. Lee. 2008. Deliberative governance for consensus building and institutional design. Administration, 47(1): 21-45.

Huxham, C. 2003. Theorizing collaboration practice. Public Management Review, 5(3): 401-423.

Huxham, C., \& S. Vangen. 2000. Leadership in the shaping and implementation of collaboration agendas: How things happen in a (not quite) joined-up world. Academy of Management Journal, 43(6): 1159-75.

Huxham, C., \& S. Vangen. 2005. Managing to collaborate: The theory and practice of collaborative advantage. New York: Routledge. 
Imperial, M. 2005. Using collaboration as a governance strategy: Lessons from six watershed management programs. Administration and Society, 37(3): 281-320.

Jun, S. 2011. An analysis of the Shihwa Sustainable Development Council as a Collaborative Public Planning Agency. Journal of the Korean Regional Science Association, 27(4): 153-176.

Kim, P. H., R. L. Pinkley, \& A. R. Fragale. 2005. Power dynamics in negotiation. Academy of Management Review, 30(4): 799-822.

Lane, C., \& R. Bachmann. 1998. Trust within and between organizations: Conceptual issues and empirical applications. Oxford: Oxford University Press.

Lasker, R. D., \& E. S. Weiss. 2003. Broadening participation in community problemsolving: A multidisciplinary model to support collaborative practice and research. Journal of Urban Health: Bulletin of the New York Academy of Medicine, 80(1): 14-60.

Lawler, E. J. 1992. Power processes in bargaining. Sociological Quarterly, 33(1): 17-34.

Lax, D. A., \& J. K. Sebenius. 1985. The power of alternatives or the limits to negotiation. Negotiation Journal, 1(2): 163-179.

Leach, W. D. 2006. Collaborative public management and democracy: Evidence from Western watershed partnerships. Public Administration Review, 66(s1): 100-110.

Leap, T., \& D. Grigsby. 1986. A conceptualization of bargaining power. Industrial and Labor Relations Review, 39(2): 202-213.

Lee, H. 2012. The Shihwa regional reclamation development project and the changes in the environmental management policy. Environmental Law and Policy, 9: 153-173.

Lee, J., \& S. Hong. 2009. The multipurposiveness of public projects and policy improvements: From absence of coordination to internalization of governing institution in the case of the Shi-hwa Lake development. Korean Public Administration Quarterly, 21(4): 1155-1176.

Lee, K., \& K. Ahn. 2007. A study of factors influencing the urban planning consensusbuilding process with an emphasis on the case of the Shi-hwa Sustainable Development Council. Urban Design, 8(2): 5-16.

Logsdon, J. 1991. Interests and interdependence in the formation of social problemsolving collaborations. Journal of Applied Behavioral Science, 27(1): 23-37.

Ma, K., \& T. Moon. 2012. An analysis of the role of the Shi-hwa Sustainable Development Council as a coordinator for conflict resolution with an emphasis on the development projects in the Shi-hwa area. Korean Policy Science Review, 16(2): 161-181.

Mitchell, B. 2005. Participatory partnerships: Engaging and empowering to enhance environmental management and quality of life? Social Indicators Research, 
71(1-3): 123-144.

Moon, C., \& S. Lim. 2003. Weaving through paradoxes: Democratization, globalization, and environmental politics in South Korea. East Asian Review, 15(2): 43-70.

Mooney, L. 1984. The social psychology of power. Sociological Spectrum, 4(1): 31-51.

Murdock, B., C. Wiessner, \& K. Sexton. 2005. Stakeholder participation in voluntary environmental agreements: Analysis of 10 Project XL case studies. Science, Technology and Human Values, 30(2): 223-250.

Norris-Tirrell, D., and J. A. Clay. 2010. Strategic collaboration in public and nonprofit administration: A practice-based approach to solving shared problems. Boca Raton, FL: Taylor and Francis.

O’Toole, L. J., Jr., \& K. J. Meier. 2004. Desperately seeking Selznick: Cooptation and the dark side of public management in networks. Public Administration Review, 64(6): 681-693.

Ozawa, P. 1993. Improving citizen participation in environmental decisionmaking: The use of transformative mediator techniques. Environment and Planning C: Government and Policy, 11(1): 103-117.

Phillips, N., \& C. Hardy. 1997. Managing multiple identities: Discourse, legitimacy and resources in the UK refugee system. Organization, 4(2): 159-185.

Purdy, J. M. 2012. A framework for assessing power in collaborative governance processes. Public Administration Review, 72(3): 409-417.

Putnam, L. L. 2004. Transformations and critical moments in negotiations. Negotiations Journal, 20(2): 275-295.

Sagoff, M. 2004. Price, principle, and the environment. Cambridge: Cambridge University Press.

Sanders, L. M. 1997. Against deliberation. Political Theory, 25(3): 347-376.

Saunders, H. 1991. We need a larger theory of negotiation: The importance of prenegotiation phases. In J. W. Breslin \& J. Z. Rubin, Negotiation Theory and Practice. Cambridge, MA: Program on Negotiation at Harvard Law School.

Steins, N. A., \& V. Edwards. 1999. Platforms for collective action in multiple-use common-pool resources. Agriculture and Human Values, 16(3): 241-255.

Susskind, L., \& J. Cruikshank. 1987. Breaking the impasse: Consensual approaches to resolving public disputes. Basic Books, New York.

Thomas, C. W. 2003. Habitat conservation plans: Certainly empowered, somewhat deliberative, questionably democratic. In A. Fung \& E. Olin Wright (eds.), Deepening Democracy: Institutional Innovations in Empowered Participatory Governance (pp. 144-172). London: Verso.

Thomson, A. M., \& J. Perry. 2006. Collaboration processes: Inside the black box. Public Administration Review, 66(s1):20-32. 
Susskind, L., \& G. McMahon (1985). The theory and practice of negotiated rulemaking. Yale Journal on Regulation, 3(1): 133-165.

Vangen, S., \& C. Huxham. 2003. Nurturing collaborative relations: Building trust in interorganizational collaboration. Journal of Applied Behavioral Science, 39(1): 5-31.

Vangen S., \& C. Huxham. 2013. Building and using the theory of collaborative advantage. In R. Keast, M. Mandell, \& R. Agranoff (eds.), Network Theory in the Public Sector: Building New Theoretical Frameworks. New York: Taylor and Francis.

Warner, J. F. 2006. More sustainable participation? Multi-stakeholder platforms for integrated catchment management. Water Resources Development, 22(1): 15-35.

Webb, A. 1991. Coordination: A problem in public sector management. Policy and Politics, 19(4): 229-241.

Weber, E. P. 2003. Bringing society back in: Grassroots ecosystem management, accountability, and sustainable communities. Cambridge, MA: MIT Press.

Weech-Maldonado, R., \& S. Merrill. 2000. Building partnerships with the community: Lessons from the Camden Health Improvement Learning Collaborative. Journal of Healthcare Management, 45(3): 189-205.

Yaffee, S. L., \& J. Wondolleck. 2003. Collaborative ecosystem planning processes in the United States: Evolution and challenges. Environments, 31(2): 59-72.

Yukl, G., \& J. B. Tracey. 1992. Consequences of influence tactics used with subordinates, peers, and the boss. Journal of Applied Psychology, 77(4): 525-535.

Zartman, W. I. 1989. Ripe for resolution. New York: Oxford University Press. 